\title{
Contributions of the immune system to the pathophysiology of traumatic brain injury - evidence by intravital microscopy
}

\author{
Susanne M. Schwarzmaier ${ }^{1,2}$ and Nikolaus Plesnila ${ }^{2,3}$ * \\ ${ }^{1}$ Department of Anesthesiology, University of Munich Medical Center, Munich, Germany \\ ${ }^{2}$ Institute for Stroke and Dementia Research (ISD), University of Munich Medical Center, Munich, Germany \\ ${ }^{3}$ Munich Cluster of Systems Neurology, Munich, Germany
}

Edited by:

Arthur Liesz, University Hospital

Munich, Germany

Reviewed by:

Jie Cui, Roskamp Institute, USA

Michael J. Whalen, Massachusetts

General Hospital, USA

*Correspondence:

Nikolaus Plesnila, Institute for Stroke and Dementia Research

(ISD), University of Munich Medical Center, Max-Lebsche Platz 30,

81377 Munich, Germany

e-mail: nikolaus.plesnila@med.uni-

muenchen.de
Traumatic brain injury (TBI) results in immediate brain damage that is caused by the mechanical impact and is non-reversible. This initiates a cascade of delayed processes which cause additional—secondary—brain damage. Among these secondary mechanisms, the inflammatory response is believed to play an important role, mediating actions that can have both protective and detrimental effects on the progression of secondary brain damage. Histological data generated extensive information; however, this is only a snapshot of processes that are, in fact, very dynamic. In contrast, in vivo microscopy provides detailed insight into the temporal and spatial patterns of cellular dynamics. In this review, we aim to summarize data which was generated by in vivo microscopy, specifically investigating the immune response following brain trauma, and its potential effects on secondary brain damage.

Keywords: brain trauma, secondary brain damage, inflammation, leukocytes, microglia, innate immune answer, in vivo imaging, intravital microscopy

\section{TRAUMATIC BRAIN INJURY}

Traumatic brain injury (TBI) remains one of the major causes of death and severe disability in industrialized countries (Bruns and Hauser, 2003; Tagliaferri et al., 2006). It results in immediate primary damage that is caused by the mechanical impact and is non-reversible. This primary contusion initiates a cascade of secondary processes on a cellular, subcellular, and molecular level which cause additional—secondary—brain damage (Kontos et al., 1981; Baethmann et al., 1988; Allan and Rothwell, 2001; Sahuquillo et al., 2001; Bramlett and Dietrich, 2004; Nortje and Menon, 2004; Werner and Engelhard, 2007; Harhangi et al., 2008; Maas et al., 2008; Greve and Zink, 2009; Shlosberg et al., 2010): Both vasogenic and cytotoxic brain edema, generated by a disruption of the blood brain barrier (BBB) or swelling of astrocytes, respectively, lead to a raise in intracranial pressure (ICP; Unterberg et al., 2004). This results in reduced cerebral blood flow (CBF) and finally ischemia (Bouma et al., 1992; Golding et al., 1999). CBF is also impaired by alterations in the cerebral microcirculation, e.g., microthrombus formation, the generation of leukocyte/platelet aggregates, and the interaction of leukocytes with the cerebral endothelium (Schwarzmaier et al., 2010, 2013). Inflammatory processes result in the production of $\mathrm{NO}$ and free radicals, and the release of chemokines and cytokines which worsen BBB disruption and tissue damage and maintain the inflammatory reaction. Further damage is mediated by apoptotic and necrotic processes in neurons, glia cells, and endothelial cells. While the contusion volume, i.e., the area of irreversible neuronal cell death, reaches its peak already in the first $24-48 \mathrm{~h}$ as demonstrated in animal models (Kochanek et al., 1995; Zweckberger et al., 2003, 2006; Engel et al., 2008; Turtzo et al., 2014), ongoing processes orchestrating both inflammatory and recovery-related mechanisms may influence functional outcome and recovery over the following days, weeks and months (Kontos et al., 1981; Allan and Rothwell, 2001; Sahuquillo et al., 2001; Bramlett and Dietrich, 2004; Nortje and Menon, 2004; Unterberg et al., 2004; Werner and Engelhard, 2007; Harhangi et al., 2008; Maas et al., 2008; Greve and Zink, 2009; Shlosberg et al., 2010).

Most data on the pathophysiology of secondary brain damage has been generated in various animal models of TBI. The two most frequently used models mimic the two main features of TBI, i.e., cortical contusion (Controlled Cortical Impact, CCI), and diffuse axon damage (fluid percussion injury, FPI). However, so far none of the available models simultaneously mimics all features of TBI-e.g., additional vessel injury or systemic hypoxia (Lighthall et al., 1989; Finnie and Blumbergs, 2002; Morales et al., 2005; Morganti-Kossmann et al., 2010).

\section{INFLAMMATION}

TBI causes tissue damage and, consequently, induces an acute as well as a chronic inflammatory reaction, including the innate and the adaptive immune system. Both protective and detrimental aspects for the progression of secondary brain damage have been associated to different aspects of the immune response, depending e.g., on the (immune) cell type, the intensity 
of activation, and on the temporal and spatial relation of the immune response in relation to the initial brain injury (Whalen et al., 1999a; Allan and Rothwell, 2001; Morganti-Kossmann et al., 2001, 2002; Konsman et al., 2007; Rivest, 2009; Loane and Byrnes, 2010; Prinz et al., 2011; de Rivero Vaccari et al., 2014; Peruzzotti-Jametti et al., 2014). In this review we will mainly focus on in vivo microscopy studies investigating the pathophysiology of TBI. To be able to put the findings after TBI in the right context, we also included some particularly relevant studies on spinal cord injury (SCI) and cerebral ischemia in our review.

\section{IN VIVO IMAGING}

The main difficulty in determining the effects of inflammatory cells on secondary brain damage following TBI lies in the nature of the employed methods: histological data provide extensive information on spatial distribution of immune cells as well as their state of activation; however, these data will always remain only a snapshot of processes that are, in fact, very dynamic. In contrast, in vivo imaging, and more specifically in vivo microscopy, provides detailed insight into the temporal and spatial patterns of cellular and sometimes subcellular dynamics in the living brain. The two main in vivo imaging techniques used in animal research are epi-fluorescence and multiphoton microscopy (Denk et al., 1990; Helmchen and Denk, 2005; Shaner et al., 2005; Misgeld and Kerschensteiner, 2006; $\mathrm{Xu}$ et al., 2007; Holtmaat et al., 2013). For epi-fluorescence microscopy, fluorophores are excited by light and emit a fluorescent signal which is detected by a CCD camera at high speed. Main shortcomings of this technique are phototoxic tissue damage caused by high excitation energy, and the acquisition of only superficial fluorescent signals, thereby allowing only imaging in two dimensions. Multiphoton microscopy overcomes these problems by an elegant method: two-or more-photons sent consecutively by a laser arrive in the focal point of the objective at almost the same time. Their combined energy results in emission of only one photon with higher energy, i.e., longer wavelength. This phenomenon-the 2-photon effect-results in emission of fluorescence only in the focal point of the objective, and in improved tissue penetration. The consequence is a greatly improved signal to noise ratio which allows imaging of photons deriving deep from brain tissue without the necessity to use high intensity excitation energy which may damage the tissue of interest.

In contrast to histological techniques, in vivo imaging needs to (a) stain the cells of interest in the living animal, (b) use surgical techniques to expose the area of interest; and (c) keep animals under anesthesia for several hours. These interventions may interfere with the evolving immune response after TBI. For example, leukocytes were mostly imaged following in vivo staining, e.g., with Rhodamine 6G (Villringer et al., 1991), while microglia were studied in most cases in mice expressing CX3CR1-GFP (Jung et al., 2000). For superficial imaging, an open cranial window preparation was employed (Wahl et al., 1985). In contrast, for multiphoton microscopy either the skull was thinned (Frostig et al., 1990), or a bone flap and the underlying dura mater were removed and a cover glass was implanted (Levasseur et al., 1975; Kienast et al., 2010); a procedure already activating microglia and influencing dendritic spine turnover (Xu et al., 2007). The maintenance of sufficient anesthesia and of physiological parameters like body temperature, mean arterial blood pressure (MABP), and arteriolar blood gases (i.e., $\mathrm{pH}, \mathrm{pO}_{2}$ and $\mathrm{pCO}_{2}$, electrolytes, etc.) both during surgery and the time of in vivo imaging is another important aspect. These parameters can significantly affect (patho-) physiological processes; consequently, their continuous monitoring and maintenance throughout in vivo imaging is important. While the body temperature is controlled and maintained in most in vivo imaging experiments discussed in this review, only very few studies provide information on MABP or blood gases (Härtl et al., 1997a,b; Utagawa et al., 2008; Schwarzmaier et al., 2010, 2013), or heart rate and oxygen saturation (Masuda et al., 2011). Since experiments including the preparation of a cranial window and/or imaging can last up to several hoursand the animal is under anesthesia for an equally long period of time-it is important that the ventilation of the animals is sufficient and adjustable to the individual animal. However, only few studies report that the animals were intubated (Masuda et al., 2011) or intubated and ventilated (Härtl et al., 1997a,b; Utagawa et al., 2008; Schwarzmaier et al., 2010, 2013; Herz et al., 2011). Accordingly, these points need to be critically taken into consideration when interpreting data obtained by in vivo imaging.

\section{CEREBRAL INFLAMMATORY RESPONSE-RESIDENT CELLS}

Microglia are the resident macrophages in the brain (Stoll and Jander, 1999; Soulet and Rivest, 2008; Ransohoff and Cardona, 2010; Kettenmann et al., 2011). Under physiological conditions, they have a ramified shape with small cell bodies and long processes which continuously scan their environment (Davalos et al., 2005; Nimmerjahn et al., 2005), monitoring synapses and responding to their functional state (Wake et al., 2009). Upon activation, microglia change both functionally and morphologically into their activated forms which are referred to as "M1" or "M2". M1 is considered to be the pro-inflammatory state, associated with actions such as phagocytosis, the presentation of antigens, and the production of reactive oxygen species (ROS) and NO. By contrast, microglia with the activation state $\mathrm{M} 2$, which is sometimes subdivided further into "acquired deactivation" and "alternative activation", are responsible for effects such as the fine tuning of inflammation, the recruitment of regulatory T-cells, and for scavenging of debris. They are also associated with the promotion of tissue remodeling or repair, and with angiogenesis (Stoll and Jander, 1999; Colton, 2009; Loane and Byrnes, 2010; Ransohoff and Cardona, 2010; David and Kroner, 2011; Kettenmann et al., 2011). Accordingly, microglia are believed to play both a beneficial and a detrimental role after brain injury, depending-among other factors such as age-both on the injury type, and the time investigated, i.e., the acute or the chronic inflammatory response (Block et al., 2007; Glezer et al., 2007; Rivest, 2009; Loane and Byrnes, 2010; Kettenmann et al., 2011; Nayak et al., 2012; Hernandez-Ontiveros et al., 2013; Peruzzotti-Jametti et al., 2014). 


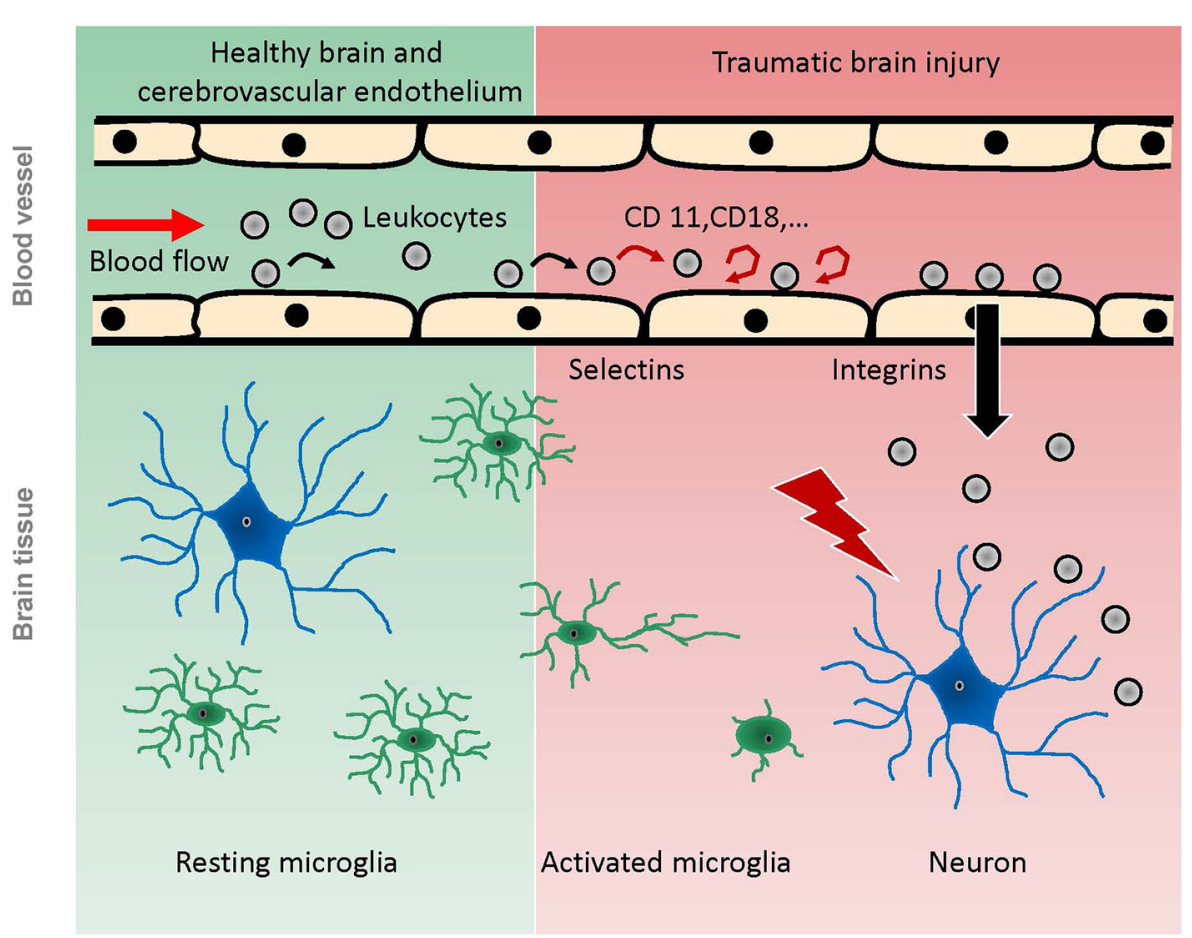

FIGURE 1 | Scheme of pathophysiological reactions of leukocytes and microglia after traumatic brain injury as demonstrated by in vivo experiments. Under physiological conditions (green background), leukocytes pass the cerebral microcirculation in undisturbed blood flow, while some of them occasionally role on the endothelium. Microglia have a ramified shape and continuously scan the brain parenchyma with their processes. Following TBI (red background), the intravascular leukocytes start rolling and adhering to the endothelium, mediated by selectins and integrins respectively. Finally, they migrate into the damaged tissue. Microglia become activated by brain trauma, extend their processes towards the site of injury, and finally migrate towards the injury, taking up an amoeboid shape.
Following brain injury, microglia extend their processes towards the damaged area as shown in vivo after laser or microelectrode injury (Davalos et al., 2005), or ex vivo on organotropic hippocampal slice cultures following MCAo (Neumann et al., 2008; Figure 1). Microglia morphologically become more amoeboid and finally migrate towards the site of injury (Kim and Dustin, 2006). These changes in morphology and/or migration resulted in encapsulation of the damaged area (Davalos et al., 2005; Kim and Dustin, 2006), or in engulfment of invading neutrophils (Neumann et al., 2008). The laser injury was performed by high laser power delivered to a dedicated area of interest for a certain time, and the microelectrode injury was induced with a glass electrode which was inserted into the cortex by a micromanipulator (Davalos et al., 2005). Both laser injury and microelectrode injury result in a very small, focal brain damage. Consequently, these techniques provide excellent models for studying very subtle alterations of cells or even subcellular processes in a well-defined area. While these studies generate valuable information on microglia and their functions, they do not mimic clinical brain injury. The dynamics of a TBI, however, can cause a much stronger and more complex damage-depending on injury severity and mechanism — which might affect or activate the resident immune cells quite differently.

Considering that TBI may also lead to cerebral ischemia, the reaction of microglia to ischemic events in vivo might also be helpful for a better understanding of the function of microglia after brain trauma. Severely decreased CBF initiated microglial de-ramification-i.e., activation-in different models of cerebral ischemia, while a moderate decrease or an increase in CBF had no visible effect on microglia and their processes (Masuda et al., 2011). Following ischemia, microglia seem to influence the fate of synapses in ischemic areas (Wake et al., 2009). The authors conclude that microglia detect the functional state of synapses and play a role in remodeling neuronal circuits. In both studies several different models of cerebral ischemia were investigated, such as photo-thrombotic stroke and global ischemia. CBF in the region of interest was assessed and directly compared and matched with alterations observed in microglia. Another study on cortical microhemorrhages induced by laser injury showed a local, inflammatory response including activated microglia, however this was limited to an area in close proximity around the lesion (Rosidi et al., 2011).

In contrast to their acute response, the chronic activation of microglia seems to mediate mainly detrimental effects, e.g., via (inadequate) release of cytotoxic chemokines, neurotoxic effects of receptor activation/upregulation (e.g., Toll-like receptors (TLRs)), or ROS production, as reviewed in detail by others (Stoll and Jander, 1999; Block et al., 2007; Rivest, 2009; Loane and Byrnes, 2010; Kettenmann et al., 2011; Giunta et al., 2012; Mannix and Whalen, 2012; Hernandez-Ontiveros et al., 2013). 
In data obtained from histological sections ex vivo, different properties of acute and chronic activation post trauma were revealed. Microglia displayed mostly a classical activation (M1) or acquired deactivation at seven and up to 28 days after FPI, but no alternative activation (Cao et al., 2012). In line with that, M2 induced by CCI peaked already at day 3-5 post injury (Turtzo et al., 2014). Inhibition of microglia activation 1 month after CCI in mice resulted in less lesion progression at 3 months post injury as assessed by MRI (Byrnes et al., 2012). Unfortunately, so far, little information is available on the chronic activation of microglia following TBI in vivo.

\section{SYSTEMIC INFLAMMATORY RESPONSE-BLOOD BORNE LEUKOCYTES}

The contributions of the systemic inflammatory response to secondary brain damage following TBI have been investigated intensively (Kochanek and Hallenbeck, 1992; Rothlein, 1997; Ransohoff and Tani, 1998; Johnson-Léger et al., 2000; Ransohoff et al., 2003; Callahan and Ransohoff, 2004; Imhof and AurrandLions, 2004; van Buul and Hordijk, 2004; David and Kroner, 2011). Within the first hours following TBI, leukocytes and leukocyte-platelet aggregates begin to roll on and adhere to the cerebrovascular endothelium (Härtl et al., 1997b; Schwarzmaier et al., 2010, 2013; Figure 1). These studies were performed using clinically relevant trauma models such as FPI and CCI, which mimic not all, but the main features induced by TBI (Lighthall et al., 1989; Finnie and Blumbergs, 2002; Morales et al., 2005; Morganti-Kossmann et al., 2010). Similar leukocyte-endothelium interactions (LEI) have been demonstrated in models of cerebral ischemia (Kataoka et al., 2004) and SAH (Ishikawa et al., 2009). In a model of liver inflammation, LEI was shown to activate cerebral microglia and alter neuronal excitability (D'Mello et al., 2013). For the development of secondary brain damage after TBI, however, rolling and adherence of leukocytes to the cerebral endothelium may have a limited pathophysiological relevance. In vivo data showed that BBB breakdown was not associated to LEI following FPI (Härtl et al., 1997a,b), which was confirmed by ex vivo data (Whalen et al., 1998, 1999b). Inhibition of leukocyte adherence to the endothelium did not have any effect on secondary lesion progression after CCI (Schwarzmaier et al., 2013). Following laser injury, leukocytes were not recruited into the injury focus but to perivascular spaces in close proximity to the injury as shown in vivo; however, this happened not before day one after injury (Kim and Dustin, 2006). There is, however, one study reporting a correlation between leukocyte adherence and vascular leakage $36 \mathrm{~h}$ following CCI in vivo (Pascual et al., 2013). In this study, however, the craniotomy for the CCI was not resealed, a procedure well known to prevent secondary brain injury after TBI (Zweckberger et al., 2003, 2006). In this setup, post trauma edema formation will not increase ICP and microcirculatory alterations are likely to differ significantly compared to a trauma model where the bone flap is resealed and intracranial hypertension is allowed to build up. These differences of pathophysiological processes with and without intracranial hypertension might well explain the differences in the observed effects of LEI.
While leukocyte rolling and adherence can be monitored by IVM, studying the migration into the affected tissue is technically demanding and has therefore been studied mostly ex vivo. Neutrophil depletion has been demonstrated to reduce secondary brain damage, but the effect only became significant at 2 weeks after CCI (Kenne et al., 2012). Another study investigating the effect of an antibody directed against a subunit of the CD11d/CD18 integrin on leukocytes reports a positive effect on lesion volume already 3 days after FPI (Utagawa et al., 2008). In a study conducted by our own laboratory, leukocytes were shown to migrate into the tissue only after secondary brain damage had already occurred (Schwarzmaier et al., 2013), findings in accordance with histological data published by others (Mathew et al., 1994; Holmin et al., 1995; Soares et al., 1995; Holmin and Mathiesen, 1999).

More conclusive in vivo data on the role of microglia vs. peripheral immune cells after SCI were presented by Evans et al. (2014). In this study, different chimeras of transgenic mice were generated in order to image either resident microglia or blood borne monocytes/macrophages and their respective contribution to the progression of the injury in vivo. The authors show that it is in fact blood-derived macrophages which facilitate secondary axon dieback, and not resident microglia. Invasion of blood borne monocytes/macrophages into the CNS was dependent on microglial TLR4 (Zhou et al., 2006). Accordingly, microglia do not only directly influence secondary brain damage, but also indirectly by recruiting blood borne immune cells.

\section{ADAPTIVE IMMUNE RESPONSE}

To date, the adaptive immune response to TBI and its contributions to secondary brain damage has not been investigated intensively. There are, however, reports indicating both a neuroprotective and a detrimental role of the adaptive immune system in the pathophysiology following SCI or in chronic neuronal diseases, which have been reviewed in detail by others (Ankeny and Popovich, 2009; Schwartz et al., 2013; Rodrigues et al., 2014; Walsh et al., 2014). Histological data suggest that adaptive immune cells migrate into the damaged tissue only after secondary brain damage has occurred (Holmin et al., 1995, 1998; Soares et al., 1995; Schwarzmaier et al., 2013).

One study investigating the behavior of T-cells in health and autoimmunity in vivo showed that naïve T-cells did not migrate into the healthy CNS, while they partly migrated into inflamed brain tissue after Experimental Autoimmune Encephalomyelitis (EAE) in vivo. In their paper, the authors show that the migratory capacity of T-cells depends more on the activation status rather than the phenotype or antigen specificity (Herz et al., 2011).

\section{SUMMARY/OUTLOOK}

TBI induces an inflammatory reaction which includes both the innate and the adaptive immune system. This inflammatory response can be roughly divided into an acute phase lasting hours to days, and a chronic phase lasting for weeks to months or even years. Upon TBI, microglia shift to different forms of 
activation, which have both detrimental and beneficial effects on secondary brain damage. By and large, the acute phase of microglia activation seems to provide various protective and beneficial mechanisms, reaching from phagocytosis to recovery and repair, while a chronic response is mainly associated with negative effects on the CNS. Following focal brain injury, data obtained in vivo demonstrate that microglia extend their processes towards the damaged area, change morphologically into a more amoeboid shape, and finally migrate towards the site of injury. This can result in the encapsulation of the damaged area or in the engulfment of invading leukocytes. While these observations were reported following laser injury or microelectrode injury, in vivo experiments on microglia activation in a clinically more relevant TBI model such as CCI or FPI are still missing. Additionally, no in vivo data is available on chronic microglia activation.

The systemic part of the inflammatory response following TBI has been studied intensively. It includes blood borne leukocytes which interact with the cerebrovascular endothelium and finally migrate into the damaged tissue. While this might influence outcome in other diseases, such as the early stage after a stroke, it does not seem to be of great importance for the mechanisms involved in secondary contusion expansion following TBI. However, a chronic response could worsen functional outcome and recovery.

Therapeutic alterations of the innate immune system might be promising not only in models of chronic inflammation, but also in TBI, specifically in view of the different forms of microglia activation after acute brain injury. Further studies are needed in order to investigate therapeutic options targeting inflammation, and to fully elucidate microglia activation in vivo following clinically relevant models of TBI.

\section{AUTHOR CONTRIBUTIONS}

Susanne M. Schwarzmaier: Review of the literature and writing the manuscript. Nikolaus Plesnila: Review of the literature and revision of the manuscript. Both authors approve the final version of the manuscript and are accountable for all aspects of the work.

\section{ACKNOWLEDGMENTS}

The authors would like to thank Joe Guerin for editing the manuscript.

\section{REFERENCES}

Allan, S. M., and Rothwell, N. J. (2001). Cytokines and acute neurodegeneration. Nat. Rev. Neurosci. 2, 734-744. doi: 10.1038/35094583

Ankeny, D. P., and Popovich, P. G. (2009). Mechanisms and implications of adaptive immune responses after traumatic spinal cord injury. Neuroscience 158, 11121121. doi: 10.1016/j.neuroscience.2008.07.001

Baethmann, A., Maier-Hauff, K., Kempski, O., Unterberg, A., Wahl, M., and Schurer, L. (1988). Mediators of brain edema and secondary brain damage. Crit. Care Med. 16, 972-978. doi: 10.1097/00003246-198810000-00008

Block, M. L., Zecca, L., and Hong, J. S. (2007). Microglia-mediated neurotoxicity: uncovering the molecular mechanisms. Nat. Rev. Neurosci. 8, 57-69. doi: 10. 1038/nrn2038

Bouma, G. J., Muizelaar, J. P., Stringer, W. A., Choi, S. C., Fatouros, P., and Young, H. F. (1992). Ultra-early evaluation of regional cerebral blood flow in severely head-injured patients using xenon-enhanced computerized tomography. J. Neurosurg. 77, 360-368. doi: 10.3171/jns.1992.77.3.0360
Bramlett, H. M., and Dietrich, W. D. (2004). Pathophysiology of cerebral ischemia and brain trauma: similarities and differences. J. Cereb. Blood Flow Metab. 24, 133-150. doi: 10.1097/01.wcb.0000111614.19196.04

Bruns, J. Jr., and Hauser, W. A. (2003). The epidemiology of traumatic brain injury: a review. Epilepsia 44(Suppl. 10), 2-10. doi: 10.1046/j.1528-1157.44.s10.3.x

Byrnes, K. R., Loane, D. J., Stoica, B. A., Zhang, J., and Faden, A. I. (2012). Delayed mGluR5 activation limits neuroinflammation and neurodegeneration after traumatic brain injury. J. Neuroinflammation 9:43. doi: 10.1186/17422094-9-43

Callahan, M. K., and Ransohoff, R. M. (2004). Analysis of leukocyte extravasation across the blood-brain barrier: conceptual and technical aspects. Curr. Allergy Asthma Rep. 4, 65-73. doi: 10.1007/s11882-004-0046-9

Cao, T., Thomas, T. C., Ziebell, J. M., Pauly, J. R., and Lifshitz, J. (2012). Morphological and genetic activation of microglia after diffuse traumatic brain injury in the rat. Neuroscience 225, 65-75. doi: 10.1016/j.neuroscience.2012.08.058

Colton, C. A. (2009). Heterogeneity of microglial activation in the innate immune response in the brain. J. Neuroimmune Pharmacol. 4, 399-418. doi: 10. 1007/s11481-009-9164-4

Davalos, D., Grutzendler, J., Yang, G., Kim, J. V., Zuo, Y., Jung, S., et al. (2005). ATP mediates rapid microglial response to local brain injury in vivo. Nat. Neurosci. 8, 752-758. doi: 10.1038/nn1472

David, S., and Kroner, A. (2011). Repertoire of microglial and macrophage responses after spinal cord injury. Nat. Rev. Neurosci. 12, 388-399. doi: 10. 1038/nrn3053

Denk, W., Strickler, J. H., and Webb, W. W. (1990). Two-photon laser scanning fluorescence microscopy. Science 248, 73-76. doi: 10.1126/science.2321027

de Rivero Vaccari, J. P., Dietrich, W. D., and Keane, R. W. (2014). Activation and regulation of cellular inflammasomes: gaps in our knowledge for central nervous system injury. J. Cereb. Blood Flow Metab. 34, 369-375. doi: 10.1038/jcbfm. 2013.227

D’Mello, C., Riazi, K., Le, T., Stevens, K. M., Wang, A., Mckay, D. M., et al. (2013). P-selectin-mediated monocyte-cerebral endothelium adhesive interactions link peripheral organ inflammation to sickness behaviors. J. Neurosci. 33, 1487814888. doi: 10.1523/jneurosci.1329-13.2013

Engel, D. C., Mies, G., Terpolilli, N. A., Trabold, R., Loch, A., De Zeeuw, C. I., et al. (2008). Changes of cerebral blood flow during the secondary expansion of a cortical contusion assessed by 14C-iodoantipyrine autoradiography in mice using a non-invasive protocol. J. Neurotrauma 25, 739-753. doi: 10.1089/neu. 2007.0480

Evans, T. A., Barkauskas, D. S., Myers, J. T., Hare, E. G., You, J. Q., Ransohoff, R. M., et al. (2014). High-resolution intravital imaging reveals that bloodderived macrophages but not resident microglia facilitate secondary axonal dieback in traumatic spinal cord injury. Exp. Neurol. 254, 109-120. doi: 10. 1016/j.expneurol.2014.01.013

Finnie, J. W., and Blumbergs, P. C. (2002). Traumatic brain injury. Vet. Pathol. 39, 679-689.

Frostig, R. D., Lieke, E. E., Ts'o, D. Y., and Grinvald, A. (1990). Cortical functional architecture and local coupling between neuronal activity and the microcirculation revealed by in vivo high-resolution optical imaging of intrinsic signals. Proc. Natl. Acad. Sci. U S A 87, 6082-6086. doi: 10.1073/pnas.87.16.6082

Giunta, B., Obregon, D., Velisetty, R., Sanberg, P. R., Borlongan, C. V., and Tan, J. (2012). The immunology of traumatic brain injury: a prime target for Alzheimer's disease prevention. J. Neuroinflammation 9:185. doi: 10.1186/17422094-9-185

Glezer, I., Simard, A. R., and Rivest, S. (2007). Neuroprotective role of the innate immune system by microglia. Neuroscience $147,867-883$. doi: 10.1016/j. neuroscience.2007.02.055

Golding, E. M., Robertson, C. S., and Bryan, R. M. Jr. (1999). The consequences of traumatic brain injury on cerebral blood flow and autoregulation: a review. Clin. Exp. Hypertens. 21, 299-332. doi: 10.3109/10641969909068668

Greve, M. W., and Zink, B. J. (2009). Pathophysiology of traumatic brain injury. Mt. Sinai J. Med. 76, 97-104. doi: 10.1002/msj.20104

Harhangi, B. S., Kompanje, E. J., Leebeek, F. W., and Maas, A. I. (2008). Coagulation disorders after traumatic brain injury. Acta Neurochir. (Wien) 150, 165-175. doi: 10.1007/s00701-007-1475-8

Härtl, R., Medary, M., Ruge, M., Arfors, K. E., and Ghajar, J. (1997a). Bloodbrain barrier breakdown occurs early after traumatic brain injury and is not related to white blood cell adherence. Acta Neurochir. Suppl. 70, 240-242. doi: 10. 1007/978-3-7091-6837-0_74 
Härtl, R., Medary, M. B., Ruge, M., Arfors, K. E., and Ghajar, J. (1997b). Early white blood cell dynamics after traumatic brain injury: effects on the cerebral microcirculation. J. Cereb. Blood Flow Metab. 17, 1210-1220. doi: 10.1097/00004647199711000-00010

Helmchen, F., and Denk, W. (2005). Deep tissue two-photon microscopy. Nat. Methods 2, 932-940. doi: 10.1038/nmeth818

Hernandez-Ontiveros, D. G., Tajiri, N., Acosta, S., Giunta, B., Tan, J., and Borlongan, C. V. (2013). Microglia activation as a biomarker for traumatic brain injury. Front. Neurol. 4:30. doi: 10.3389/fneur.2013.00030

Herz, J., Paterka, M., Niesner, R. A., Brandt, A. U., Siffrin, V., Leuenberger, T., et al. (2011). In vivo imaging of lymphocytes in the CNS reveals different behaviour of naive T cells in health and autoimmunity. J. Neuroinflammation 8:131. doi: 10 . 1186/1742-2094-8-131

Holmin, S., and Mathiesen, T. (1999). Long-term intracerebral inflammatory response after experimental focal brain injury in rat. Neuroreport 10, 1889-1891. doi: 10.1097/00001756-199906230-00017

Holmin, S., Mathiesen, T., Shetye, J., and Biberfeld, P. (1995). Intracerebral inflammatory response to experimental brain contusion. Acta Neurochir. (Wien) 132, 110-119. doi: 10.1007/bf01404857

Holmin, S., Söderlund, J., Biberfeld, P., and Mathiesen, T. (1998). Intracerebral inflammation after human brain contusion. Neurosurgery 42, 291-298. doi: 10. 1097/00006123-199809000-00159

Holtmaat, A., Randall, J., and Cane, M. (2013). Optical imaging of structural and functional synaptic plasticity in vivo. Eur. J. Pharmacol. 719, 128-136. doi: 10. 1016/j.ejphar.2013.07.020

Imhof, B. A., and Aurrand-Lions, M. (2004). Adhesion mechanisms regulating the migration of monocytes. Nat. Rev. Immunol. 4, 432-444. doi: 10.1038/nril375

Ishikawa, M., Kusaka, G., Yamaguchi, N., Sekizuka, E., Nakadate, H., Minamitani, H., et al. (2009). Platelet and leukocyte adhesion in the microvasculature at the cerebral surface immediately after subarachnoid hemorrhage. Neurosurgery 64, 546-553. doi: 10.1227/01.neu.0000337579.05110.f4

Johnson-Léger, C., Aurrand-Lions, M., and Imhof, B. A. (2000). The parting of the endothelium: miracle, or simply a junctional affair? J. Cell Sci. 113(Pt. 6), 921-933.

Jung, S., Aliberti, J., Graemmel, P., Sunshine, M. J., Kreutzberg, G. W., Sher, A., et al. (2000). Analysis of fractalkine receptor CX(3)CR1 function by targeted deletion and green fluorescent protein reporter gene insertion. Mol. Cell. Biol. 20, 41064114. doi: $10.1128 / \mathrm{mcb} .20 .11 .4106-4114.2000$

Kataoka, H., Kim, S. W., and Plesnila, N. (2004). Leukocyte-endothelium interactions during permanent focal cerebral ischemia in mice. J. Cereb. Blood Flow Metab. 24, 668-676. doi: 10.1097/01.wcb.0000117812.35136.5b

Kenne, E., Erlandsson, A., Lindbom, L., Hillered, L., and Clausen, F. (2012). Neutrophil depletion reduces edema formation and tissue loss following traumatic brain injury in mice. J. Neuroinflammation 9:17. doi: 10.1186/1742-2094-9-17

Kettenmann, H., Hanisch, U. K., Noda, M., and Verkhratsky, A. (2011). Physiology of microglia. Physiol. Rev. 91, 461-553. doi: 10.1152/physrev.00011. 2010

Kienast, Y., von Baumgarten, L., Fuhrmann, M., Klinkert, W. E., Goldbrunner, R., Herms, J., et al. (2010). Real-time imaging reveals the single steps of brain metastasis formation. Nat. Med. 16, 116-122. doi: 10.1038/nm.2072

Kim, J. V., and Dustin, M. L. (2006). Innate response to focal necrotic injury inside the blood-brain barrier. J. Immunol. 177, 5269-5277. doi: 10.4049/jimmunol. 177.8.5269

Kochanek, P. M., and Hallenbeck, J. M. (1992). Polymorphonuclear leukocytes and monocytes/macrophages in the pathogenesis of cerebral ischemia and stroke. Stroke 23, 1367-1379. doi: 10.1161/01.str.23.9.1367

Kochanek, P. M., Marion, D. W., Zhang, W., Schiding, J. K., White, M., Palmer, A. M., et al. (1995). Severe controlled cortical impact in rats: assessment of cerebral edema, blood flow and contusion volume. J. Neurotrauma 12, 10151025. doi: 10.1089/neu.1995.12.1015

Konsman, J. P., Drukarch, B., and Van Dam, A. M. (2007). (Peri)vascular production and action of pro-inflammatory cytokines in brain pathology. Clin. Sci. (Lond.) 112, 1-25. doi: 10.1042/cs20060043

Kontos, H. A., Wei, E. P., and Povlishock, J. T. (1981). Pathophysiology of vascular consequences of experimental concussive brain injury. Trans. Am. Clin. Climatol. Assoc. 92, 111-121.

Levasseur, J. E., Wei, E. P., Raper, A. J., Kontos, A. A., and Patterson, J. L. (1975). Detailed description of a cranial window technique for acute and chronic experiments. Stroke 6, 308-317. doi: 10.1161/01.str.6.3.308
Lighthall, J. W., Dixon, C. E., and Anderson, T. E. (1989). Experimental models of brain injury. J. Neurotrauma 6, 83-97. doi: 10.1089/neu.1989.6.83

Loane, D. J., and Byrnes, K. R. (2010). Role of microglia in neurotrauma. Neurotherapeutics 7, 366-377. doi: 10.1016/j.nurt.2010.07.002

Maas, A. I., Stocchetti, N., and Bullock, R. (2008). Moderate and severe traumatic brain injury in adults. Lancet Neurol. 7, 728-741. doi: 10.1016/s14744422(08)70164-9

Mannix, R. C., and Whalen, M. J. (2012). Traumatic brain injury, microglia and Beta amyloid. Int. J. Alzheimers Dis. 2012:608732. doi: 10.1155/2012/608732

Masuda, T., Croom, D., Hida, H., and Kirov, S. A. (2011). Capillary blood flow around microglial somata determines dynamics of microglial processes in ischemic conditions. Glia 59, 1744-1753. doi: 10.1002/glia.21220

Mathew, P., Graham, D. I., Bullock, R., Maxwell, W., Mcculloch, J., and Teasdale, G. (1994). Focal brain injury: histological evidence of delayed inflammatory response in a new rodent model of focal cortical injury. Acta Neurochir. Suppl. (Wien) 60, 428-430. doi: 10.1007/978-3-7091-9334-1_116

Misgeld, T., and Kerschensteiner, M. (2006). In vivo imaging of the diseased nervous system. Nat. Rev. Neurosci. 7, 449-463. doi: 10.1038/nrn1905

Morales, D. M., Marklund, N., Lebold, D., Thompson, H. J., Pitkanen, A., Maxwell, W. L., et al. (2005). Experimental models of traumatic brain injury: do we really need to build a better mousetrap? Neuroscience 136, 971-989. doi: 10.1016/j. neuroscience.2005.08.030

Morganti-Kossmann, M. C., Rancan, M., Otto, V. I., Stahel, P. F., and Kossmann, T. (2001). Role of cerebral inflammation after traumatic brain injury: a revisited concept. Shock 16, 165-177. doi: 10.1097/00024382-200116030-00001

Morganti-Kossmann, M. C., Rancan, M., Stahel, P. F., and Kossmann, T. (2002). Inflammatory response in acute traumatic brain injury: a double-edged sword. Curr. Opin. Crit. Care 8, 101-105. doi: 10.1097/00075198-200204000-00002

Morganti-Kossmann, M. C., Yan, E., and Bye, N. (2010). Animal models of traumatic brain injury: is there an optimal model to reproduce human brain injury in the laboratory? Injury 41(Suppl 1), S10-13. doi: 10.1016/j.injury.2010. 03.032

Nayak, D., Zinselmeyer, B. H., Corps, K. N., and Mcgavern, D. B. (2012). In vivo dynamics of innate immune sentinels in the CNS. Intravital 1, 95-106. doi: 10. 4161/intv. 22823

Neumann, J., Sauerzweig, S., Ronicke, R., Gunzer, F., Dinkel, K., Ullrich, O., et al. (2008). Microglia cells protect neurons by direct engulfment of invading neutrophil granulocytes: a new mechanism of CNS immune privilege. J. Neurosci. 28, 5965-5975. doi: 10.1523/jneurosci.0060-08.2008

Nimmerjahn, A., Kirchhoff, F., and Helmchen, F. (2005). Resting microglial cells are highly dynamic surveillants of brain parenchyma in vivo. Science 308, 13141318. doi: $10.1126 /$ science. 1110647

Nortje, J., and Menon, D. K. (2004). Traumatic brain injury: physiology, mechanisms, and outcome. Curr. Opin. Neurol. 17, 711-718. doi: 10.1097/00019052200412000-00011

Pascual, J. L., Murcy, M. A., Li, S., Gong, W., Eisenstadt, R., Kumasaka, K., et al. (2013). Neuroprotective effects of progesterone in traumatic brain injury: blunted in vivo neutrophil activation at the blood-brain barrier. Am. J. Surg. 206, 840-845; discussion 845-846. doi: 10.1016/j.amjsurg.2013.07.016

Peruzzotti-Jametti, L., Donega, M., Giusto, E., Mallucci, G., Marchetti, B., and Pluchino, S. (2014). The role of the immune system in central nervous system plasticity after acute injury. Neuroscience. doi: 10.1016/j.neuroscience.2014.04. 036. [Epub ahead of print].

Prinz, M., Priller, J., Sisodia, S. S., and Ransohoff, R. M. (2011). Heterogeneity of CNS myeloid cells and their roles in neurodegeneration. Nat. Neurosci. 14, 12271235. doi: 10.1038/nn.2923

Ransohoff, R. M., and Cardona, A. E. (2010). The myeloid cells of the central nervous system parenchyma. Nature 468, 253-262. doi: 10.1038/nature09615

Ransohoff, R. M., Kivisakk, P., and Kidd, G. (2003). Three or more routes for leukocyte migration into the central nervous system. Nat. Rev. Immunol. 3, 569581. doi: 10.1038/nril130

Ransohoff, R. M., and Tani, M. (1998). Do chemokines mediate leukocyte recruitment in post-traumatic CNS inflammation? Trends Neurosci. 21, 154-159. doi: 10.1016/s0166-2236(97)01198-3

Rivest, S. (2009). Regulation of innate immune responses in the brain. Nat. Rev. Immunol. 9, 429-439. doi: 10.1038/nri2565

Rodrigues, M. C., Sanberg, P. R., Cruz, L. E., and Garbuzova-Davis, S. (2014). The innate and adaptive immunological aspects in neurodegenerative diseases. J. Neuroimmunol. 269, 1-8. doi: 10.1016/j.jneuroim.2013.09.020 
Rosidi, N. L., Zhou, J., Pattanaik, S., Wang, P., Jin, W., Brophy, M., et al. (2011). Cortical microhemorrhages cause local inflammation but do not trigger widespread dendrite degeneration. PLoS One 6:e26612. doi: 10.1371/journal.pone.00 26612

Rothlein, R. (1997). Overview of leukocyte adhesion. Neurology 49, S3-S4. doi: 10. 1212/wnl.49.5_suppl_4.s3

Sahuquillo, J., Poca, M. A., and Amoros, S. (2001). Current aspects of pathophysiology and cell dysfunction after severe head injury. Curr. Pharm. Des. 7, 14751503. doi: 10.2174/1381612013397311

Schwartz, M., Kipnis, J., Rivest, S., and Prat, A. (2013). How do immune cells support and shape the brain in health, disease and aging? J. Neurosci. 33, 1758717596. doi: 10.1523/jneurosci.3241-13.2013

Schwarzmaier, S. M., Kim, S. W., Trabold, R., and Plesnila, N. (2010). Temporal profile of thrombogenesis in the cerebral microcirculation after traumatic brain injury in mice. J. Neurotrauma 27, 121-130. doi: 10.1089/neu.2009.1114

Schwarzmaier, S. M., Zimmermann, R., Mcgarry, N. B., Trabold, R., Kim, S. W., and Plesnila, N. (2013). In vivo temporal and spatial profile of leukocyte adhesion and migration after experimental traumatic brain injury in mice. $J$. Neuroinflammation 10:32. doi: 10.1186/1742-2094-10-32

Shaner, N. C., Steinbach, P. A., and Tsien, R. Y. (2005). A guide to choosing fluorescent proteins. Nat. Methods 2, 905-909. doi: 10.1038/nmeth819

Shlosberg, D., Benifla, M., Kaufer, D., and Friedman, A. (2010). Blood-brain barrier breakdown as a therapeutic target in traumatic brain injury. Nat. Rev. Neurol. 6, 393-403. doi: 10.1038/nrneurol.2010.74

Soares, H. D., Hicks, R. R., Smith, D., and Mcintosh, T. K. (1995). Inflammatory leukocytic recruitment and diffuse neuronal degeneration are separate pathological processes resulting from traumatic brain injury. J. Neurosci. 15, 82238233.

Soulet, D., and Rivest, S. (2008). Microglia. Curr. Biol. 18, R506-R508. doi: 10. 1016/j.cub.2008.04.047

Stoll, G., and Jander, S. (1999). The role of microglia and macrophages in the pathophysiology of the CNS. Prog. Neurobiol. 58, 233-247. doi: 10.1016/s03010082(98)00083-5

Tagliaferri, F., Compagnone, C., Korsic, M., Servadei, F., and Kraus, J. (2006). A systematic review of brain injury epidemiology in Europe. Acta Neurochir. (Wien) 148, 255-268; discussion 268. doi: 10.1007/s00701-005-0651-y

Turtzo, L. C., Lescher, J., Janes, L., Dean, D. D., Budde, M. D., and Frank, J. A. (2014). Macrophagic and microglial responses after focal traumatic brain injury in the female rat. J. Neuroinflammation 11:82. doi: 10.1186/1742-2094-11-82

Unterberg, A. W., Stover, J., Kress, B., and Kiening, K. L. (2004). Edema and brain trauma. Neuroscience 129, 1021-1029. doi: 10.1016/j.neuroscience.2004. 06.046

Utagawa, A., Bramlett, H. M., Daniels, L., Lotocki, G., Dekaban, G. A., Weaver, L. C., et al. (2008). Transient blockage of the CD11d/CD18 integrin reduces contusion volume and macrophage infiltration after traumatic brain injury in rats. Brain Res. 1207, 155-163. doi: 10.1016/j.brainres.2008.02.057

van Buul, J. D., and Hordijk, P. L. (2004). Signaling in leukocyte transendothelial migration. Arterioscler. Thromb. Vasc. Biol. 24, 824-833. doi: 10.1161/01.atv. $0000122854.76267 .5 \mathrm{c}$

Villringer, A., Dirnagl, U., Them, A., Schürer, L., Krombach, F., and Einhäupl, K. M. (1991). Imaging of leukocytes within the rat brain cortex in vivo. Microvasc. Res. 42, 305-315. doi: 10.1016/0026-2862(91)90064-i

Wahl, M., Unterberg, A., and Baethmann, A. (1985). Intravital fluorescence microscopy for the study of blood-brain-barrier function. Int. J. Microcirc. Clin. Exp. 4, 3-18.
Wake, H., Moorhouse, A. J., Jinno, S., Kohsaka, S., and Nabekura, J. (2009). Resting microglia directly monitor the functional state of synapses in vivo and determine the fate of ischemic terminals. J. Neurosci. 29, 3974-3980. doi: 10.1523/jneurosci. 4363-08.2009

Walsh, J. T., Watson, N., and Kipnis, J. (2014). T cells in the central nervous system: messengers of destruction or purveyors of protection? Immunology 141, 340344. doi: 10.1111/imm.12187

Werner, C., and Engelhard, K. (2007). Pathophysiology of traumatic brain injury. Br. J. Anaesth. 99, 4-9. doi: 10.1093/bja/aem131

Whalen, M. J., Carlos, T. M., Clark, R. S., and Kochanek, P. M. (1999a). An acute inflammatory response to the use of granulocyte colony-stimulating factor to prevent infections in patients with brain injury: what about the brain? Crit. Care Med. 27, 1014-1018. doi: 10.1097/00003246-199905000-00049

Whalen, M. J., Carlos, T. M., Kochanek, P. M., Clark, R. S., Heineman, S., Schiding, J. K., et al. (1999b). Neutrophils do not mediate blood-brain barrier permeability early after controlled cortical impact in rats. J. Neurotrauma 16, 583-594. doi: 10.1089/neu.1999.16.583

Whalen, M. J., Carlos, T. M., Kochanek, P. M., and Heineman, S. (1998). Bloodbrain barrier permeability, neutrophil accumulation and vascular adhesion molecule expression after controlled cortical impact in rats: a preliminary study. Acta Neurochir. Suppl. 71, 212-214. doi: 10.1007/978-3-7091-6475-4_61

Xu, H. T., Pan, F., Yang, G., and Gan, W. B. (2007). Choice of cranial window type for in vivo imaging affects dendritic spine turnover in the cortex. Nat. Neurosci. 10, 549-551. doi: 10.1038/nprot.2007.186

Zhou, H., Lapointe, B. M., Clark, S. R., Zbytnuik, L., and Kubes, P. (2006). A requirement for microglial TLR4 in leukocyte recruitment into brain in response to lipopolysaccharide. J. Immunol. 177, 8103-8110. doi: 10.4049/jimmunol.177. 11.8103

Zweckberger, K., Erös, C., Zimmermann, R., Kim, S. W., Engel, D., and Plesnila, N. (2006). Effect of early and delayed decompressive craniectomy on secondary brain damage after controlled cortical impact in mice. J. Neurotrauma 23, 1083 1093. doi: 10.1089/neu.2006.23.1083

Zweckberger, K., Stoffel, M., Baethmann, A., and Plesnila, N. (2003). Effect of decompression craniotomy on increase of contusion volume and functional outcome after controlled cortical impact in mice. J. Neurotrauma 20, 1307-1314. doi: $10.1089 / 089771503322686102$

Conflict of Interest Statement: The Guest Associate/Review Editor Arthur Liesz declares that, despite being affiliated to the same institution as the authors, the review process was handled objectively and no conflict of interest exists. The authors declare that the research was conducted in the absence of any commercial or financial relationships that could be construed as a potential conflict of interest.

Received: 31 July 2014; accepted: 13 October 2014; published online: 04 November 2014.

Citation: Schwarzmaier SM and Plesnila N (2014) Contributions of the immune system to the pathophysiology of traumatic brain injury - evidence by intravital microscopy. Front. Cell. Neurosci. 8:358. doi: 10.3389/fncel.2014.00358

This article was submitted to the journal Frontiers in Cellular Neuroscience.

Copyright $(1) 2014$ Schwarzmaier and Plesnila. This is an open-access article distributed under the terms of the Creative Commons Attribution License (CC BY). The use, distribution and reproduction in other forums is permitted, provided the original author(s) or licensor are credited and that the original publication in this journal is cited, in accordance with accepted academic practice. No use, distribution or reproduction is permitted which does not comply with these terms. 